\title{
The protective role of prosocial behaviors on antisocial behaviors: The mediating effects of deviant peer affiliation
}

\author{
Gustavo Carlo $^{\mathrm{a}, *}$, Maria Vicenta Mestre ${ }^{\mathrm{b}}$, Meredith M. McGinley ${ }^{\mathrm{c}}$, \\ Ana Tur-Porcar ${ }^{\mathrm{b}}$, Paula Samper ${ }^{\mathrm{b}}$, Deanna Opal ${ }^{\mathrm{d}}$ \\ a University of Missouri, 410 Gentry Hall, Columbia, MO 65211, USA \\ ${ }^{\mathrm{b}}$ Universitat de Valencia, Spain \\ ${ }^{\mathrm{c}}$ The Chicago School for Professional Psychology, USA \\ ${ }^{\mathrm{d}}$ University of Nebraska-Lincoln, USA
}

\section{A R T I C L E I N F O}

\section{Article history:}

Available online 12 March 2014

\section{Keywords:}

Prosocial behaviors

Aggression

Delinquency

Peers

\begin{abstract}
A B S T R A C T
Prosocial behaviors, actions intended to help others, may serve a protective function against association with deviant peers and subsequent delinquent and antisocial behaviors. The present study examined the relations among specific types of prosocial behaviors, deviant peer affiliation, and delinquent and aggressive behaviors. Six hundred and sixtysix adolescents ( $46 \%$ girls; $M$ age $=15.33, S D=.47$ ) from Valencia, Spain completed questionnaires of prosocial behaviors, affiliation with deviant peers, antisocial behaviors, and aggression. Results showed that antisocial behaviors were negatively related only to specific forms of prosocial behaviors. Further analyses showed that deviant peer affiliation mediated the relations between compliant prosocial behavior and delinquency and aggression. Although altruism was not directly related to delinquency and aggression, it was indirectly linked to the behaviors via deviant peer affiliation. Discussion focuses on the relevance of specific forms of prosocial behaviors to antisocial behaviors and the risk of deviant peers for prosocial youth.

( 2014 The Foundation for Professionals in Services for Adolescents. Published by Elsevier
\end{abstract} Ltd. All rights reserved.

Interest in understanding the factors that reduce violence and antisocial behaviors among adolescents remains an important area of research among scholars. A growing recent trend is the examination of links between prosocial behaviors (i.e., actions intended to benefit others) and problem behaviors (such as aggression, delinquency) in youth (Barber, Eccles, \& Stone, 2001; Carlo, Crockett, Wilkinson, \& Beal, 2011; Dodge, 1983; Eccles \& Barber, 1999). In general, such research suggests that youth who engage in high levels of prosocial behaviors (such as volunteerism, sharing, donating) are less likely to exhibit a number of social problem behaviors. These findings may have important implications for the development of intervention programs aimed at reducing violence and problem behaviors in adolescence. However, little is known regarding the mechanisms that may explain the links between prosocial and antisocial behaviors. The present study was designed to address that gap by examining the role of deviant peer group affiliation in the relations between prosocial and antisocial behaviors.

Among other theories, symbolic interaction and social cognitive theories suggest that individuals strive for behavioral consistency (Bandura, 1986; Carlo \& Randall, 2001; Mead, 1934) such that one might expect that youth are motivated to behave in ways that promote and maintain such behaviors. For example, youth who engage in high levels of prosocial

\footnotetext{
* Corresponding author.

E-mail address: carlog@missouri.edu (G. Carlo).
} 
behaviors may be more apt to behave prosocially, and less likely to engage antisocially, in the future to maintain consistency in their beliefs, attitudes, and behaviors. Such youth may be more apt to interact with peers who endorse and reinforce prosocial behaviors and may avoid peers with contradicting beliefs, attitudes, and actions. A sustained pattern of peer interactions may therefore result in relatively stable individual differences in prosocial and antisocial behaviors over time.

Indeed, research demonstrates that prosocial youth are more prone to endorse prosocial values and mores that foster compassion and consideration of others (Carlo et al., 2011; Johnston \& Krettenauer, 2011; Padilla-Walker \& Carlo, 2007), which may promote moral beliefs and sense of self that may be incompatible with antisocial behaviors. Consistent with these notions, there is evidence that youth who exhibit high levels of prosocial behaviors tend to be highly sympathetic (i.e., feelings of sorrow or concern for others), exhibit high levels of moral reasoning (i.e., thinking about dilemmas of justice and welfare) and perspective taking (i.e., understanding the thoughts, feelings, and social situation of others), relatively socially skilled and popular, and are more likely to deem themselves as a caring, moral persons (Carlo, 2006; Eisenberg, Fabes, \& Spinrad, 2006). Moreover, there is ample evidence that there are relatively stable individual differences in prosocial behaviors across childhood and adolescence (see Carlo, 2006; Eisenberg et al., 2006). These personal and interpersonal, prosocial and socially competent characteristics may serve to prevent individuals with relatively high levels of prosocial tendencies from manifesting relatively high levels of aggressive and delinquent behaviors.

With regards to the relations between prosocial and antisocial behaviors, one might expect a general, inverse association between such behaviors. Although some youth may be apt to engage in both forms of social behaviors (Coie \& Kupersmidt, 1983; Dodge, 1983; Hawley, Card, \& Little, 2007; Kokko, Tremblay, Lacourse, Nagin, \& Vitaro, 2006; Veenstra et al., 2008), there are conceptual reasons to expect a general inverse link. Conceptually, antisocial behaviors (e.g., aggression, delinquency) would be expected to be less desirable among youth who have prosocial tendencies, especially if their prosocial tendencies are characterized by internalized social mores and norms, a strong sensitivity towards others, and/or a low expectation of rewards from engaging in antisocial behaviors. Indeed, there is substantial evidence that aggression and prosocial behaviors are inversely related (Crick, 1996; Eron \& Huesmann, 1984; McGinley \& Carlo, 2007; Persson, 2005). Moreover, youth who engage in relatively high levels of prosocial behaviors score lower on delinquency (e.g., Ellis \& Zarbatany, 2007; Lacourse et al., 2006; Mahoney, 2000; Mason, Hitchings, McMahon, \& Spoth, 2007; see Sussman, Pokhrel, Ashmore, \& Brown, 2006). In contrast to youth who exhibit relatively high levels of prosocial behaviors, delinquent youth tend to show relatively low levels of perspective taking, sympathy, and moral reasoning (Miller \& Eisenberg, 1988; Stams et al., 2006). Taken together, the accumulating evidence suggests that understanding the relations between prosocial and antisocial behaviors might help us understand ways to prevent delinquent and aggressive behaviors.

Recently, however, developmental scholars have begun to examine the correlates of specific forms of prosocial behaviors (Boxer, Tisak, \& Goldstein, 2004; Hawley et al., 2007). Carlo and his colleagues (Carlo, Knight, McGinley, Zamboanga, \& Jarvis, 2010; Carlo \& Randall, 2002), for example, identified six types of prosocial behaviors. These types include the tendency to help when requested (compliant), in emotionally evocative contexts (emotional), in crisis situations (dire), in front of others (public), without others' awareness (anonymous), and without expectation of self reward (altruistic). Thus far, research findings suggest distinct factors that correspond to each prosocial behavior type (Carlo et al., 2010). More importantly, investigators also have shown significant heterogeneity in the correlates of these prosocial tendencies (e.g., Carlo, Hausmann, Christiansen, \& Randall, 2003; Eisenberg et al., 2009; McGinley \& Carlo, 2007). These findings suggest that there may be differential relations between specific forms of prosocial behaviors and specific problem behaviors.

Based primarily on prosocial development theories and research (Carlo, 2006; Eisenberg et al., 2006), of the different forms of prosocial behaviors, one might expect youth who engage in relatively high levels of altruistic behaviors to be least likely to engage in antisocial behaviors, including aggression and delinquency. This is because altruistic behaviors reflect an orientation towards the needs of others, low expectancies of self reward from antisocial behaviors, and internalized moral norms (e.g., caring and concern for others) consistent with altruistic behaviors that contradict antisocial norms. Similarly, compliant forms of prosocial behaviors require a willingness to socially conform and to engage in normative social behaviors. Given the tendency for problem youth to defy authority figures and social norms and conventions (see Rowe, Costello, Angold, Copeland, \& Maughan, 2010 for a review), one might expect an inverse link between compliant prosocial behaviors and both aggression and delinquency.

Despite the expected inverse relations between both compliant and altruistic prosocial behaviors and antisocial behaviors, sparse research currently exists on this issue. McGinley and Carlo (2007) showed that physical aggression was significantly negatively related to altruistic and compliant forms of helping among young adults (i.e., college students). In a study of preschoolers, Persson (2005) found that altruistic motivated but not requested (compliant) behaviors were significantly, negatively related to aggression (see also Boxer et al., 2004). These findings provide suggestive evidence that specific forms of prosocial behavior are linked to aggressive behaviors. However, no other direct research exists and researchers have not directly examined the relations between specific types of prosocial behaviors and delinquency in adolescents. Thus, primarily on the basis of theory, inverse relations were expected between compliant and altruistic prosocial behaviors and both aggressive and delinquent behaviors.

Although the evidence demonstrates links between prosocial and antisocial behaviors, research is needed on possible mediating mechanisms that can explain such relations. Developmental scholars have identified affiliation with deviant peers as a risk variable that is associated with both aggressive and delinquent behaviors in youth (Patterson, Dishion, \& Yoerger, 2000). Deviant peers may encourage and reinforce social behaviors and beliefs that contradict prosocial norms and 
conventions. Furthermore, such peers often provide social scripts that foster antisocial tendencies (Dishion, McCord, \& Poulin, 1999) and mitigate prosocial tendencies (especially towards out-group members). Therefore, youth who score high on prosocial behaviors may be less attracted to affiliate with deviant peers. More specifically, engagement in compliant and altruistic forms of prosocial behaviors may be particularly prone to influence from deviant peers because such behaviors may be viewed as socially conforming and youth who engage in such actions may be particularly less prone to affiliate with deviant peers. Despite the evidence that affiliation with deviant peers is associated with antisocial behaviors (Granic \& Patterson, 2006; Moffitt, 1993), research on the links between deviant peer affiliation and prosocial behaviors is scarce (for an exception see Jessor, Turbin, \& Costa, 1998).

To our knowledge, this is the first study that directly examines the mediating role of deviant peer affiliation in the relations between specific forms of prosocial behaviors and antisocial behaviors. The findings can inform our theories of prosocial and antisocial development in adolescence, and provide avenues for developing more effective prevention intervention efforts to reduce antisocial behaviors during this age period.

Conceptually, the relations between compliant and altruistic prosocial behaviors and both aggressive and delinquent behaviors were expected to be mediated by deviant peer affiliation. In general, both forms of prosocial behaviors were expected to be negatively linked to deviant peer affiliation and deviant peer affiliation, which in turn, was expected to be positively associated with both aggressive and delinquent behaviors. A-priori expectations regarding the relations of dire, emotional, anonymous, and public forms of prosocial behaviors to antisocial tendencies were less clear because of the lack of prior research on these relations. However, conceptually, antisocial youth may be prone to public, and less prone to anonymous, forms of prosocial behaviors because public behaviors have been linked to gaining other peers' approval (Carlo \& Randall, 2002). Furthermore, antisocial youth may be less likely to engage in dire and emotional prosocial behaviors because such behaviors are strongly linked to empathy and sympathy tendencies (see Carlo, 2006).

Moreover, because gender differences in prosocial and antisocial behaviors are expected based on gender socialization theory and prior research findings (Coie \& Dodge, 1998; Eisenberg et al., 2006), we also explored gender differences in the relations between prosocial and antisocial behaviors. However, given the lack of prior research on gender differences in the relations between specific forms of prosocial behaviors and antisocial behaviors, no a-priori hypotheses regarding gender differences in these relations were proposed.

\section{Method}

\section{Participants and procedure}

The sample was 666 students ( $46 \%$ girls, $M$ age $=15.33, S D=.47$ ) from public and private schools located in different geographic zones within the school district of Valencia, Spain. Most were from two-parent households (73\%; 33\% singleparent households). Mothers' education level was 35\% less than high school diploma, 37\% high school diploma or equivalent, and 26\% at least some university education. The majority self-identified from Spain $(n=507 ; n=111$ from Latin America, e.g., Ecuador (50), Bolivia (20), Colombia (15), Argentina (7); $n=19$ from Eastern European countries, e.g., Romania (13), Bulgaria (3)). Trained experimenters administered the self-report surveys in classrooms (completion time of approximately $50 \mathrm{~min})$.

\section{Measures}

All measures have been adapted for use and validated in samples of adolescents from Spain (e.g., Del Barrio, Moreno, \& López, 2001; Mestre, Pérez, Frías \& Samper, 1999; Mestre, Samper, Frias, \& Tur, 2009; Mestre et al., 2002).

\section{Prosocial tendencies}

The Prosocial Tendencies Measure Revised (PTM-R) (Carlo et al., 2003) was administered to assess six different prosocial behaviors: emotional, altruistic, dire, compliant, public and anonymous. The measure includes 21 Likert-type items with five response options $(1=$ does not describe you at all to $5=$ describes you very well). Public prosocial behaviors were defined as behaviors intended to benefit others enacted in the presence of others (three items; sample item, "I can help others best when people are watching me"). Anonymous prosocial behaviors were defined as the tendency to help others without other people's knowledge (four items; "I think that helping others without them knowing is the best type of situation"). Dire prosocial behaviors refer to helping others under emergency or crisis situations (three items; "I tend to help people who are in real crisis or need"). Emotional prosocial behaviors are behaviors intended to benefit others enacted under emotionally evocative situations (five items; "It makes me feel good when I can comfort someone who is very upset"). Compliant prosocial behaviors refer to helping others when asked to ( 2 items; "When people ask me to help them, I don't hesitate"). Altruistic refers to helping others when there is little or no perceived potential for a direct, explicit reward to the self (four items; item is reverse scored: "I believe that donating goods or money works best when I get some benefit"). Cronbach's alphas ranged from .61 to .79 . 
Deviant friends

This measure (Prinstein \& Wang, 2005) lists nine items $(\alpha=.92)$ regarding deviant activities their three closest friends may have done or experienced in the past year: hurt someone else on purpose, threatened to hurt someone, gotten into trouble with the police, ruined or damaged other people's things or school property on purpose, have broken into a place like a car or building to steal something, have stolen something worth more than ten dollars, have smoked cigarettes, have gotten drunk, and have used marijuana. Possible frequency responses ranged from $0=$ none of my closest friends to $3=$ three of my closest friends. Scores were averaged.

\section{Aggression}

The measure of aggression (Caprara \& Pastorelli, 1993; Del Barrio et al., 2001) contains 15 items that assess physical and verbal aggression (e.g., "I kick and punch others."). Items were on a 3-point scale, anchored by 1 (Never) to 3 (Frequently). After dropping some items due to low inter-item correlations, the resulting items were averaged into a score of aggression (Cronbach's alpha $=.85)$.

\section{Delinquency}

The Measure of Self-Reported Delinquency (Osgood, McMorris, \& Potenza, 2002) consists of $14(\alpha=.87$ ) items that are commonly used in assessing delinquent activities. The items include: hit an instructor, serious fight, gang group fight, hurt someone badly, robbery, theft greater than $\$ 50$, theft less than $\$ 50$, shoplifting, joy riding, theft of car part, trespassing, arson, school vandalism, and workplace vandalism. The questions ask students to report how often during the past 12 months they have participated in each of these activities on a scale from $1=$ Not at all to $5=5$ or More times. Scores were averaged.

\section{Results}

\section{Preliminary analyses}

Descriptive statistics and zero-order correlations among the main study variables are presented in Table 1. Altruistic prosocial behaviors were negatively related to deviant peer affiliation, aggression, and delinquency. Compliant and emotional prosocial behaviors were negatively linked to aggression and delinquency. Compliant was also marginally (at the $p<.10$ level) negatively related to deviant peer affiliation. Dire was negatively related to aggression. In contrast, delinquency was positively related to anonymous and public (marginally) prosocial behaviors. Deviant peer affiliation was positively related to aggression and delinquency. In addition, aggression was positively related to delinquency.

In general, prosocial behaviors were positively interrelated. However, public, anonymous, and emotional behaviors were negatively related to altruistic behaviors. Girls expressed greater mean dire, emotional, compliant and altruistic prosocial behaviors than boys, whereas boys expressed greater mean public and anonymous prosocial behaviors than girls. Additionally, boys endorsed greater aggression, delinquency and deviant peer affiliation (marginally) than girls.

\section{Main model tests}

To examine the possible mediating effects of deviant friends on the relations between prosocial tendencies and delinquency and aggression, structural equation model tests were conducted. Using Mplus 6.1 (Muthén \& Muthén, 1998-2010), we tested two path analyses for 1) altruism and 2) compliant prosocial behavior as these were the only two prosocial variables significantly or marginally significantly related to the mediator variable (deviant peer affiliation). The bootstrap procedure was implemented in Mplus in order to determine whether these indirect effects were statistically significant. An indirect effect was

Table 1

Descriptive statistics and correlation matrix of aggression, delinquency, deviant peers, and prosocial behaviors.

\begin{tabular}{|c|c|c|c|c|c|c|c|c|c|c|}
\hline & 1 & 2 & 3 & 4 & 5 & 6 & 7 & 8 & 9 & 10 \\
\hline 1. Dire & - & & & & & & & & & \\
\hline 2. Emotional & $.66^{*}$ & - & & & & & & & & \\
\hline 3. Compliant & $.55^{*}$ & $.62^{*}$ & - & & & & & & & \\
\hline 4. Public & $.12^{*}$ & $.14^{*}$ & -.05 & - & & & & & & \\
\hline 5. Anonymous & $.28^{*}$ & $.24^{*}$ & $.20^{*}$ & $.22^{*}$ & - & & & & & \\
\hline 6. Altruistic & -.05 & $-.11^{*}$ & $.10^{*}$ & $-.53^{*}$ & $-.18^{*}$ & - & & & & \\
\hline 7. Deviant peers & -.01 & -.01 & $-.08+$ & .05 & .05 & $-.12^{*}$ & - & & & \\
\hline 8. Aggression & $-.10^{*}$ & $-.10^{*}$ & $-.19^{*}$ & .03 & .04 & $-.09^{*}$ & $.39 *$ & - & & \\
\hline 9. Delinquency & -.06 & $-.10^{*}$ & $-.16^{*}$ & $.07+$ & $.11^{*}$ & $-.14^{*}$ & $.45^{*}$ & $.32^{*}$ & - & \\
\hline 10. Gender & $.10^{*}$ & $.23^{*}$ & $.22^{*}$ & $-.20^{*}$ & $-.08^{*}$ & $.22^{*}$ & $-.08+$ & $-.10^{*}$ & $-.16^{*}$ & - \\
\hline Mean & 3.43 & 3.47 & 3.72 & 2.03 & 2.40 & 4.74 & .88 & 1.39 & 1.30 & 1.46 \\
\hline SD & .86 & .84 & .97 & .91 & .84 & 1.18 & .71 & .28 & .46 & - \\
\hline
\end{tabular}

${ }^{*} p<.05$.

${ }^{+} p<.10$.

Note. Gender coded as $1=$ male and $2=$ female. 
significant if the $95 \%$ confidence interval for the standard error fell outside of zero for that particular indirect effect (Mackinnon, Lockwood, Hoffman, West, \& Sheets, 2002). Gender was included as a control variable in these mediation analyses.

The overall model fit the data perfectly (i.e., a saturated model). For altruistic prosocial tendencies, such tendencies were negatively related to deviant peer affiliation, which in turn predicted aggression and delinquency (Fig. 1). The 95\% confidence interval for the standard error estimate of the indirect effect fell outside of zero for the path predicting aggression $(-.020$, $-.003)$ and delinquency $(-.039,-.006)$. Compliant prosocial tendencies were negatively related to deviant peer affiliation, aggression and delinquency (Fig. 1). Deviant peer affiliation in turn predicted both aggression and delinquency. The 95\% confidence interval for the standard error estimate of the indirect effect fell outside of zero for the path predicting aggression $(-.020,-.001)$ and delinquency $(-.041,-.001)$. Multigroup analyses were conducted to examine whether there were significant differences in the path coefficients for boys and girls, but no significant differences were evident.

\section{Discussion}

As expected, the findings showed that compliant and altruistic forms of prosocial behaviors showed the strongest links to antisocial behaviors. In contrast, public, anonymous, emotional, and dire forms of prosocial behavior were not significantly related to antisocial behaviors. Moreover, there was support for the notion that the negative associations between compliant and altruistic prosocial behaviors and both aggression and delinquency among adolescents were partially accounted for by affiliation with deviant peers. The findings yield suggestive evidence that prosocial behaviors can protect youth from affiliating with deviant peers and subsequent antisocial tendencies. These findings provide several new insights for theory and implications for program interventions on the links between prosocial and antisocial outcomes in adolescents.

Although prior research had documented the overall negative relations between prosocial and aggressive behaviors, few studies had directly examined specific forms of prosocial behaviors. The model tests revealed that only compliant and altruistic prosocial behaviors were significant predictors. The fact that compliant and altruistic forms of prosocial behaviors were relatively strongly, inversely associated with antisocial behaviors suggests that there may be unique characteristics of these prosocial behaviors that distinguish them from the other forms of prosocial behaviors. Compliant prosocial behaviors are considered actions that often require some level of social comformity and respect for authority, which might be antithetical to antisocial tendencies. However, youth who exhibit relatively low levels of compliant behaviors may be particularly susceptible to deviant peers who may exhibit similar action tendencies and beliefs that may foster antisocial behaviors. Given other research that suggests early expression of oppositional defiant and noncomformity tendencies in antisocial youth (ZahnWaxler, Usher, Suomi, \& Cole, 2005), future research could examine the possible developmental progression in expressions of compliant and defiant tendencies across childhood and adolescence. Early detection of low levels of compliant forms of prosocial behaviors could serve as a marker of risk for affiliation with deviant peers and subsequent antisocial behaviors.

In contrast, the negative associations between altruistic behaviors and deviant peers and antisocial behaviors may be due to the selfless versus selfish orientation of prosocial tendencies. These findings are consistent with prior research linking altruistic behaviors to aggressive behaviors in adolescence (Boxer et al., 2004). Altruistic behaviors are often expressed at a high cost to the self and are actions without a primary concern for self rewards. Although some deviant peers (e.g., gang members) may engage in altruistic actions to protect their in-group members, the expression of such actions is limited to a relatively select group of individuals who are deemed worthy of such beneficial actions. In general, then, one might expect that youth who exhibit relatively high levels of altruistic behaviors may be less attracted or avoid deviant peers who might not value such socially conventional or normative actions unless they serve their own or the peer group's purpose. This explanation is consistent with prior research that delinquents show lower scores on moral reasoning that non-delinquents (e.g., Stams et al., 2006). Further research is needed to investigate the motives underlying prosocial behaviors to better explain their links to antisocial tendencies.
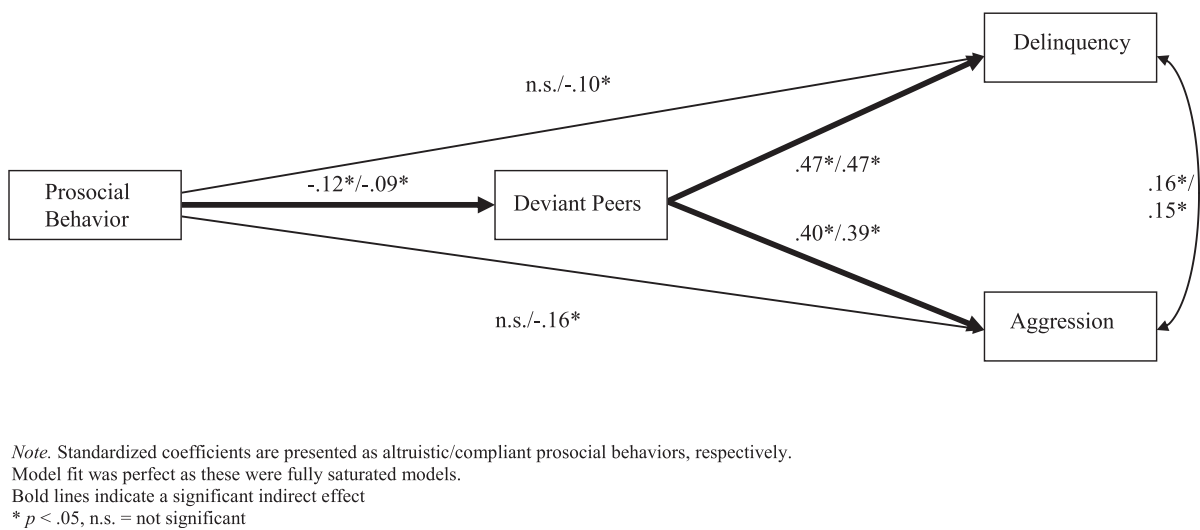

Fig. 1. Path model of the mediating role of deviant peer affiliation in the relations between prosocial behaviors and delinquent and aggressive behaviors. 
As expected, deviant peer affiliation accounted for the relations between prosocial behaviors and antisocial tendencies. These findings are in accord with prior research on the risks of affiliating with deviant peers for antisocial development (e.g., Moffitt, 1993; Patterson et al., 2000). Whereas much of the prior research has focused on early socialization agents and their influence (e.g., parents, peers) on deviant peer affiliation, the present findings show evidence that youth who frequently engage in specific forms of prosocial behaviors are also less likely to affiliate with deviant peers, and in turn, are less likely to exhibit antisocial tendencies. These mediating relations are consistent with social cognitive and feedback models (e.g., Bandura, 1986; Carlo \& Randall, 2001) that suggest that the expression of social behaviors can have consequences for subsequent actions. In this case, youth who frequently express compliant and altruistic prosocial behaviors may avoid deviant peers and less prone to their antisocial activities because prosocial actions are inconsistent with the norms and mores of antisocial youth. Clearly, however, more rigorous studies (e.g., longitudinal) are needed to adequately test these models.

The examination of specific forms of prosocial behaviors demonstrates that compliant (directly and indirectly) and altruistic (indirectly) prosocial behaviors were most strongly linked to delinquency and aggression. These findings yield additional evidence that not all forms of prosocial behaviors are related to antisocial behaviors (e.g., Boxer et al., 2004; McGinley \& Carlo, 2007). Taken together with sparse prior studies, the present findings undermine some approaches (e.g., Jessor et al., 1998) that suggest that there are latent behavior factors for prosocial/conventional and antisocial behaviors, respectively, or approaches that suggest that prosocial and aggressive behaviors are on one continuum (e.g., Eron \& Huesmann, 1984). Although further research is needed, the findings suggest that the absence of problem behaviors does not equate to the presence of prosocial behaviors and vice versa (Kokko et al., 2006; c.f. Consortium on the School-Based Promotion of Social Competence, 1994). Thus, for example, a reduction in one set of behaviors (e.g., aggression) does not automatically increase the other set of behaviors (e.g., prosocial behaviors). This notion suggests that an effective program that reduces aggressive behaviors does not guarantee a parallel increase in prosocial behaviors, unless the program has an explicit component designed to promote prosocial behaviors.

In general, gender differences in prosocial and antisocial behaviors were consistent with gender socialization theories and prior research findings. Girls scored higher on emotional, dire, compliant, and altruistic behaviors than boys, and boys scored higher than girls on public and anonymous prosocial behaviors. Scholars have asserted that girls are generally socialized to express nurturance and compliance tendencies, and to be oriented more towards emotionally evocative and needs-based situations than boys (Eagly \& Crowley, 1986; Maccoby \& Jacklin, 1974). In contrast, boys tend to exhibit more instrumental forms of prosocial behaviors than girls (Eagly \& Crowley, 1986)—these findings are consistent with the notion that helping in front of others could prove to have instrumental value to gain the approval of others (such as their peers or authority figures). The higher levels of delinquent and aggressive behaviors in boys relative to girls are also in accord with previous findings (Coie \& Dodge, 1998) though there are mixed findings that suggest that girls might engage in some specific forms of aggression more than boys (Crick, 1996; Lansford et al., 2012). However, despite the main effects of gender on these behaviors, there were no gender differences in the relations between prosocial and delinquent behaviors. These latter findings suggest that boys and girls who report high levels of compliant and altruistic prosocial behaviors are both susceptible to lower levels of delinquency, and to the mediating role of deviant peer affiliation.

There were several study limitations to the present findings. First, the cross-sectional, correlational study design seriously limits the ability to infer causal relations. More rigorous research (e.g., using longitudinal designs) is needed to better infer cause-and-effect relations. For example, there is a need to understand whether earlier demonstrations of aggressive behaviors lead to later, lower levels of prosocial behaviors or vice versa, and there is the possibility that such relations are bidirectional. Second, the constructs in the present study were assessed using self-report, paper-and-pencil measures. Future research using multiple methods (such as observational measures or parent, teacher, or peer report measures) is desirable to replicate the findings. And third, although the relatively large sample was recruited across the school district in Valencia, Spain, the findings may not be generalizable to the broader population of youth in Spain or from other countries. Studies designed to test the model in a broader sample of Spanish youth and in youth from other countries would allow for direct confirmation of the findings.

Nonetheless, the present findings add to our understanding of the links between prosocial and antisocial behaviors in youth. On a theoretical level, the present findings suggest that the importance of studying specific forms of prosocial behaviors. Among the various forms investigated in the present study, compliant and altruistic were most strongly associated with antisocial tendencies. These findings add to the mounting evidence on the importance of more nuanced models of prosocial behaviors to treat such actions as distinct. Moreover, the present findings have important implications for the development of interventions designed to reduce antisocial behaviors and simultaneously promote more constructive prosocial behaviors in adolescence. For example, program developers could develop programs that teach youth the benefits of engaging in prosocial behaviors. Such preventive intervention efforts could dissuade youth from engaging in antisocial behaviors. However, the present findings suggest that fostering compliant and altruistic behaviors may be most effective in preventing affiliating with deviant peers and from engaging in subsequent aggressive and delinquent behaviors.

\section{Acknowledgment}

The authors greatly appreciate the assistance of Elisabeth Malonda Vidal and the cooperation of the educational centres in Valencia. Funding support was provided by an I+D Projects for Research Teams of Excellence, PROMETEO Program (Reference: PROMETEO/2011/2009), Department of Education, Generalitat Valenciana to Maria Mestre. 


\section{References}

Bandura, A. (1986). Social foundations of thought and action: A social cognitive theory. Englewood Cliffs, NJ: Prentice-Hall.

Barber, B. L., Eccles, J. S., \& Stone, M. R. (2001). Whatever happened to the jock, the brain, and the princess? Young adult pathways linked to adolescent activity involvement and social identity. Journal of Adolescent Research, 16, 429-455.

Boxer, P., Tisak, M. S., \& Goldstein, S. E. (2004). Is it bad to be good? An exploration of aggressive and prosocial behavior subtypes in adolescence. Journal of Youth and Adolescence, 33, 91-100.

Caprara, G. V., \& Pastorelli, C. (1993). Early emotional instability, prosocial behavior, and aggression: some methodological aspects. European Journal of Personality, 7, 19-36.

Carlo, G. (2006). Care-based and altruistically-based morality. In M. Killen, \& J. G. Smetana (Eds.), Handbook of moral development (pp. 551-579). Mahwah, NJ: Lawrence Erlbaum Associates.

Carlo, G., Crockett, L. J., Wilkinson, J. L., \& Beal, S. J. (2011). The longitudinal relationships between rural adolescents' prosocial behaviors and young adult substance use. Journal of Youth and Adolescence, 40, 1192-1202.

Carlo, G., Hausmann, A., Christiansen, S., \& Randall, B. A. (2003). Sociocognitive and behavioral correlates of a measure of prosocial tendencies for adolescents. Journal of Early Adolescence, 23, 107-134.

Carlo, G., Knight, G. P., McGinley, M., Zamboanga, B. L., \& Jarvis, L. H. (2010). The multidimensionality of prosocial behaviors and evidence of measurement equivalence in Mexican American and European American early adolescents. Journal of Research on Adolescence, 20, 334-358.

Carlo, G., \& Randall, B. (2001). Are all prosocial behaviors equal? A socioecological developmental conception of prosocial behaviors. In F. Columbus (Ed.), Advances in psychology research (Vol. II); (pp. 252-270). Huntington, NY: Nova Science Publishers.

Carlo, G., \& Randall, B. A. (2002). The development of a measure of prosocial behaviors for late adolescents. Journal of Youth and Adolescence, 31, 31-44.

Coie, J., \& Dodge, K. A. (1998). Aggression and antisocial behavior. In W. Damon (Series ed.) \& N. Eisenberg (Vol. ed.), Handbook of child psychology, Vol. 3. Social emotional and personality development (5th ed., pp. 779-862). New York: Wiley.

Coie, J. D., \& Kupersmidt, J. B. (1983). A behavioral analysis of emerging social status in boys' groups. Child Development, 54, 1400-1416.

Consortium on the School-Based Promotion of Social Competence. (1994). The school-based promotion of social competence: theory, research, practice and policy. In R. J. Haggerty, L. Sherrod, N. Garmezy, \& M. Rutter (Eds.), Stress risk and resilience in children and adolescents: Processes, mechanisms, and interaction. New York: Cambridge University Press.

Crick, N. (1996). The role of overt aggression, relational aggression, and prosocial behavior in the prediction of children's future social adjustment. Child Development, 67, 2317-2327.

Del Barrio, V., Moreno, C., \& López, R. (2001). Evaluación de la agresión e inestabilidad emocional en niños españoles y su relación con la depresión [Assessment of aggression and emotional instability in Spanish children and its relationship with depression]. Clínica y Salud, 13, 33-50.

Dishion, T. J., McCord, J., \& Poulin, F. (1999). When interventions harm: peer groups and problem behaviors. American Psychologist, 54, 755-764.

Dodge, K. A. (1983). Behavioral antecedents of peer social status. Child Development, 54, 1386-1399.

Eagly, A. H., \& Crowley, M. (1986). Gender and helping behavior: a meta-analytic review of the social psychological literature. Psychological Bulletin, 100, 283-308.

Eccles, J. S., \& Barber, B. L. (1999). Student council, volunteering, basketball, or marching band: what kind of extracurricular involvement matters? Journal of Adolescent Research, 14, 10-43.

Eisenberg, N., Fabes, R. A., \& Spinrad, T. L. (2006). Prosocial development. In (6th ed.), Handbook of child psychology: Social, emotional, and personality, development (Vol. 3); (pp. 646-718) Hoboken, NJ: John Wiley \& Sons Inc.

Eisenberg, N., Sallquist, J., French, D. C., Purwono, U., Suryanti, T., \& Pidada, S. (2009). The relations of majority-minority group status and having an otherreligion friend to Indonesian youths' socioemotional functioning. Developmental Psychology, 45, 248-259.

Ellis, W., \& Zarbatany, L. (2007). Peer group status as a moderator of group influence on children's deviant, aggressive, and prosocial behavior. Child Development, 78, 1240-1254.

Eron, L. D., \& Huesmann, L. R. (1984). The relation of prosocial behavior to the development of aggression and psychopathology. Aggressive Behavior, 10, 201-211.

Granic, I., \& Patterson, G. R. (2006). Toward a comprehensive model of antisocial development: a dynamic systems approach. Psychological Review, 113, 101131.

Hawley, P. H., Card, N. A., \& Little, T. D. (2007). The allure of a mean friend: relationship quality and processes of aggressive adolescents with prosocial skills. International Journal of Behavioral Development, 31, 22-32.

Jessor, R., Turbin, M. S., \& Costa, F. M. (1998). Risk and protection in successful outcomes among disadvantaged adolescents. Applied Developmental Science, 2 , 194-208.

Johnston, M., \& Krettenauer, T. (2011). Moral self and moral emotion expectancies as predictors of anti- and prosocial behaviour in adolescence: a case for mediation? European Journal of Developmental Psychology, 8, 228-243.

Kokko, K., Tremblay, R. E., Lacourse, E., Nagin, D. S., \& Vitaro, F. (2006). Trajectories of prosocial behavior and physical aggression in middle childhood: links to adolescent school dropout and physical violence. Journal of Research on Adolescence, 16, 403-428.

Lacourse, E., Nagin, D. S., Vitaro, F., Côté, S., Arseneault, L., \& Tremblay, R. E. (2006). Prediction of early-onset deviant peer group affiliation: a 12-year longitudinal study. Archives of General Psychiatry, 63, 562-568.

Lansford, J. E., Skinner, A. T., Sorbring, E., Giunta, L., Deater-Deckard, K., Dodge, K. A., et al. (2012). Boys' and girls' relational and physical aggression in nine countries. Aggressive Behavior, 38, 298-308.

Maccoby, E. E., \& Jacklin, C. N. (1974). The psychology of sex differences. Stanford, CA: Stanford University Press.

Mackinnon, D. P., Lockwood, C. M., Hoffman, J. M., West, S. G., \& Sheets, V. (2002). A comparison of methods to test mediation and other intervening variable effects. Psychological Methods, 7, 83-104.

Mahoney, J. L. (2000). Participation in school extracurricular activities as a moderator in the development of antisocial patterns. Child Development, 71, 502516.

Mason, W. A., Hitchings, J. E., McMahon, R. J., \& Spoth, R. L. (2007). A test of three alternative hypotheses regarding the effects of early delinquency on adolescent psychosocial functioning and substance involvement. Journal of Abnormal Child Psychology, 35, 831-843.

McGinley, M., \& Carlo, G. (2007). Two sides of the same coin? The relations between prosocial and physically aggressive behaviors. Journal of Youth and Adolescence, 36, 337-349.

Mead, G. H. (1934). Mind, self, and society. Chicago: University of Chicago Press.

Mestre, V., Samper, P., Frias, M. D., \& Tur, A. (2009). Are women more empathetic than men? A longitudinal study in adolescence. The Spanish Journal of Psychology, 12, 76-83.

Miller, P. A., \& Eisenberg, N. (1988). The relation of empathy to aggression and externalizing/antisocial behavior. Psychological Bulletin, 103, 324-344.

Moffitt, T. E. (1993). Adolescence-limited and life-course-persistent antisocial behavior: a developmental taxonomy. Psychological Review, 100, 674-701.

Osgood, D. W., McMorris, B. J., \& Potenza, M. T. (2002). Analyzing multiple-item measures of crime and deviance I: item response theory scaling. Journal of Quantitative Criminology, 18, 267-296.

Padilla-Walker, L. M., \& Carlo, G. (2007). Personal values as a mediator between parent and peer expectations and adolescent behaviors. Journal of Family Psychology, 21, 538-541.

Patterson, G. R., Dishion, T. J., \& Yoerger, K. (2000). Adolescent growth in new forms of problem behavior: macro- and micro-peer dynamics. Prevention Science, 1, 3-13.

Persson, G. E. B. (2005). Developmental perspectives on prosocial and aggressive motives in preschoolers' peer interactions. International Journal of Behavioral Development, 29, 80-91. 
Prinstein, M. J., \& Wang, S. S. (2005). False consensus and adolescent peer contagion: examining discrepancies between perceptions and actual reported levels of friends' deviant and health risk behaviors. Journal of Abnormal Child Psychology, 33, 293-306.

Rowe, R., Costello, E., Angold, A., Copeland, W. E., \& Maughan, B. (2010). Developmental pathways in oppositional defiant disorder and conduct disorder. Journal of Abnormal Psychology, 119, 726-738.

Stams, G. J. M. M., Brugman, D., Dekovic, M., van Rosmalen, L., van der Laan, P., \& Gibbs, J. C. (2006). The moral judgment of juvenile delinquents: a metaanalysis. Journal of Abnormal Child Psychology, 34, 697-713.

Sussman, S., Pokhrel, P., Ashmore, R. D., \& Brown, B. B. (2006). Adolescent peer group identification and characteristics: a review of the literature. Addictive Behaviors, 32, 1602-1627.

Veenstra, R., Lindenberg, S., Oldehinkel, A. J., De Winter, A. F., Verhulst, F. C., \& Ormel, J. (2008). Prosocial and antisocial behavior in preadolescence: teachers' and parents' perceptions of the behavior of girls and boys. International Journal of Behavioral Development, 32, $243-251$.

Zahn-Waxler, C., Usher, B., Suomi, S., \& Cole, P. M. (2005). Intersections of biology and behavior in young children's antisocial patterns: the role of development, gender, and socialization. In D. M. Stoff, \& E. J. Susman (Eds.), Developmental psychobiology of aggression (pp. 141-160). New York: Cambridge University Press. 